\title{
Local-Best Available Techniques: a standard broad performance assessment methodology under Best Available Techniques
}

\author{
A. Cikankowitz \& V. Laforest \\ Department of Science, Information and Technology of the Environment, \\ Ecole Nationale Supérieure des Mines, Saint-Etienne, France
}

\begin{abstract}
The implementation of the Integrated Pollution Prevention and Control (IPPC) directive mandates that industries use techniques that have the same effectiveness as Best Available Techniques (BAT). BAT represents the combination of technical processes and management practices with overall positive environmental and cost benefits.

Article 13 of the IPPC directive is about the revision for initial permit conditions. To comply, industries should adopt a rigorous approach to justify to the authorities that all of their existing techniques are equivalent to BAT environmental performances. This analysis must be done technique by technique. For this, technical guides have been established at the European level: the BREF. Unfortunately, these documents are not easy to use or particularly clear. Therefore, the aim of this research project is to develop an environmental performance process assessment methodology in order to compare and then validate in house processes as BAT.

Our methodology will be tested on wastewater treatment processes for metal finishing sectors. This decision making tool emphasizes the cross media effects and thus corresponds to an integrated approach for the IPPC directive.

Keywords: IPPC directive, Best Available Techniques (BAT), environmental performances assessment, environmental and cost benefits, metal finishing industry.
\end{abstract}




\section{Introduction}

\subsection{From the European directive to the industrial application}

The Integrated Pollution Prevention and Control (IPPC) directive came into effect in 1996 [1]. It was founded upon two basic principles: using an integrated approach and the application of the Best Available Techniques (BAT).

The spirit of the IPPC is to integrate environmental protection at the European level via a process of industrial permits for each of the most polluting industrial activities mentioned in appendix I. These licenses must be based on BAT as defined in article 2.11. All the European Union countries must transcribe the regulations of the IPPC into their own laws at the national level. Since the $30^{\text {th }}$ of October 1999, the IPPC directive has had to be implemented in all new activities (even modifications may have to adhere if they have a significant impact on the environment).

In September 2007, only 43\% of the 5000 IPPC industries in France were in compliance with the IPPC directive. This is in spite of the fact that the integrated approach of the environmental French legislative is the inspiration for the European directive. Indeed, both operators and environmental authorities have difficulties in understanding and defining the BAT concept.

A common interpretation of the BAT concept is to concede that only the techniques given in the BREF are BAT. BREF are European references whereas the BATs are applied at an installation scale.

To define concretely article 13 of the IPPC directive concerning the update of the industrial licensing, France has set up the "working report" [2], which must be effectuated every 10 years. In this report, the industries concerned have to prove their techniques comply with the environmental performance of BAT determined by BREF [3]. Thanks to feedback from the French institution (20052007), working reports are still incomplete as regards the concept of BAT notably concerning the compliance to performance. Industries do not have methodology to justify using of BAT, even though they do have and understand the twelve considerations mentioned in the appendix IV of the IPPC directive [4]. Surprisingly, these recommendations are almost never by the operators $[5,6]$.

\subsection{The L-BAT legitimacy}

The commission has frequently warned member states that progress with implementation of the IPPC directive, adopted 11 years ago, suffers from "serious shortcomings", especially, the inadequate application of BAT to control pollution releases [7]. This reinforces the aim of our research project to clarify and strengthen the concept of BAT for industries and environmental authorities by developing a clearer and user-friendly assessment methodology, the L-BAT (Local-BAT). A voluntary working group has been created in November 2006 to validate the methodology and to favour relationships among public authorities and operators at National and European level. 
This article is laid out as follows: first, in chapter two describes the developed L-BAT methodology (set-up and major practical environmental management tools) which contains many qualitative and quantitative criteria, indicators and parameters connected into a "top-down" hierarchy. Then, a multi-criteria analysis is carried out in order to assess the environmental, technical and economical contribution of processes. In the next section, for a metal finishing workshop a qualitative performance assessment methodology is proposed which takes into account the vulnerability of the local natural environment. Finally, future perspectives of this research project are discussed.

\section{The L-BAT methodology}

\subsection{Definition of environmental performance}

The IPPC directive insists on the concept of environmental performance. Moreover, the major stakes of the IPPC are three-fold: BAT concept, integrated approach and local constraints. Then, in spite of an objective for emission limit values (ELV), the application of the IPPC obliges industries to consider these stakes when assessing environmental management. In fact, in addition to ELV, industries have to prove that the means to reach these objectives have the same performances as BAT.

How to determine environmental performance? The standard ISO 14031 [7] defines the concept of environmental performance as a result of the management of the entire environmental impact of a system [...]. Briefly, this is a process to facilitate operating decisions regarding an organization's environmental performance by selecting indicators, collecting and analysing data, assessing information against environmental performance criteria, reporting and periodically reviewing and improving this process. Evidently, this is a complex method and a crucial approach of the environmental management process. With the increase in the application and interest in sustainable development, the concept of environmental performance has been commonly utilized to evaluate the general consequences for firms. For the IPPC, the notion of environmental performance is directly related to the socio-economic aspect. In addition, this promotes the implementation of dynamic cleaner production strategies.

\subsection{Construction of the L-BAT methodology}

Consequently, to simplify the definition and the characterization of the BAT and thus diminish the difficulties met by operators at the factory or plant level an adequate methodology has been initiated supported by a multi-criteria analysis or decision aid.

\subsubsection{Definition of objectives}

First of all, the study of the European and the French regulatory context of the implementation of the IPPC directive make it easier to define the BAT concept. Four standard objectives have been defined which correspond rigorously to this approach: the prevention and the limitation of the environmental impacts of the 
process of production and decontamination (objective 1), prevention of risks (objective 2), maintaining of the quality of productivity (objective 3 ) as well as environmental costs constraints (objective 4). Inexorably, technical, environmental and economic performances should be aggregated to guarantee a blanket level of performance under the BAT concept.

\subsubsection{Defining objectives, criteria, indicators and parameters}

The appendix 4 of the IPPC directive provides 12 considerations to be taken into account to assess the level of environmental performance of existing techniques. Nevertheless, this information is not homogenous and consequently not easy to use $[5,6]$. Therefore, our list of terms is based on these considerations and moreover organized into criteria, indicators and parameters that satisfy precisely the four objectives aforementioned. The terms are derived from general to specific (figure 1). The definitions of these terms are suggested - Objective: a mandatory goal, Criteria: main themes which precisely state the objectives and step up the way to reach the goals - Indicators: relative quantitative and qualitative values derived from parameters and/or measures - Parameters (static) or variable (dynamic): measured or assessed data providing information to the indicators.

\subsubsection{The framework for the L-BAT methodology}

Many qualitative and quantitative terms are derived from the objectives and are classified into a hierarchy, namely, a "top-down" approach. The figure 1 presents an extract of the hierarchy for the $\mathrm{n}^{\circ} 1$ objective. Saaty [9] mentioned that a better way to understand complicated systems is to break them down into

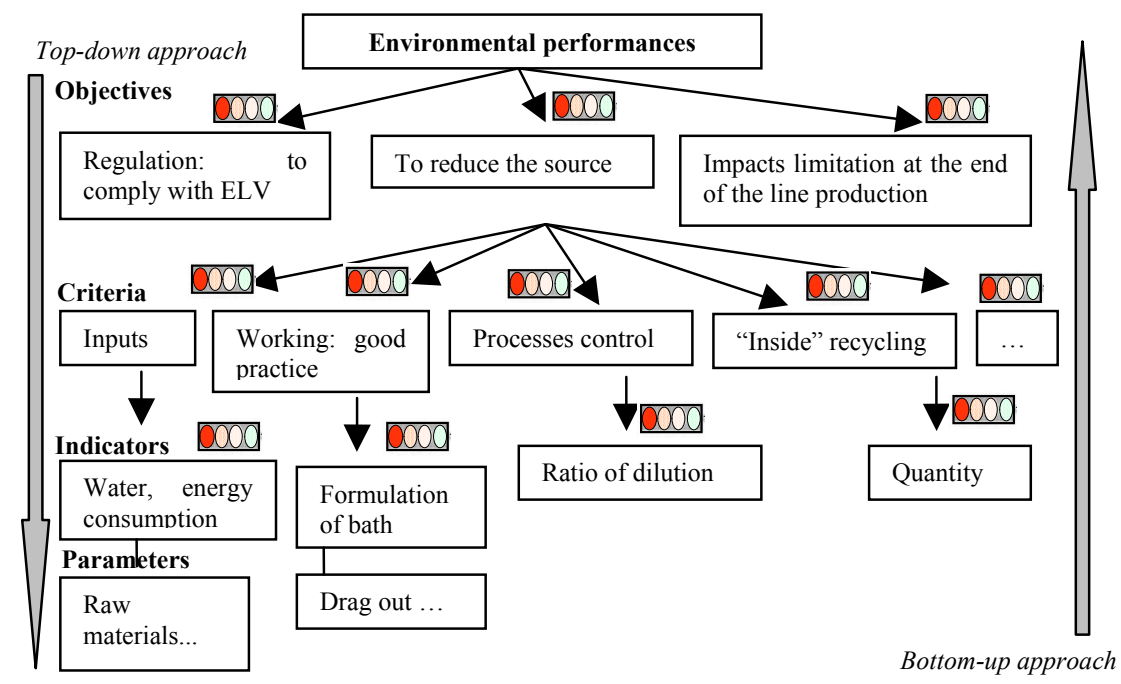

Figure 1: The top-down approach. 
components. He notes that there are no rules then to construct a hierarchy. Plus, this is an appropriate tool to organize plenty of terms in a logical order [9].

The environmental criteria are not the same according to the level considered. Some environmental criteria have not been studied, namely those related to the global environmental impact where pollution spreads beyond the immediate surroundings of installation. Criteria, such as the greenhouse effect, destruction of the ozone layer, enrichment of water, acidification, which are commonly evaluated with a Life Cycle Assessment methodology [10,14] are not implemented in the L-BAT because the metal finishing industry is not a major source of airborne emissions except $\mathrm{NO}_{\mathrm{x}}, \mathrm{HCl}, \mathrm{HF}$ and acid particulates from pickling operations or hexavalent chromium mist released from hexavalent chromium plating for example.

The terms are not chosen through diverse existing environmental performance methodologies but have been defined with BREF, technical guides, experts, etc.

In a hierarchy the number of levels is not limited. There is always a possibility to modify the structure or to add new criteria [9].

Each step of the approach could be used no matter what activity is evaluated. The characteristics of each sector is considered at the last step when the determining the parameters

\subsubsection{How to combine the criteria? A "bottom-up" approach}

There are different methods to aggregate information. With battery of indicators, it is preferable to use a multi-criteria structure rather than constructing composite indicators. This simplifies the way to use these terms or combine them to be able to take a decision in order to reach finally a required level of environmental performance. Besides, according to Girardin et al. [11] the laying out of a dashboard takes less time than the construction of composite indicators. Moreover, the dashboard is also easier to understand as well as very practical for operators to use. Opting for a multi-criteria structure, more comprehensible results are provided which are also well organized as compared to the diversified and complex environmental impacts of techniques or processes.

For each existing technique, the operators give values to parameters or indicators according to a "bottom-up" strategy (figure 1). The evaluation is done with a multi-criterially and is accomplished at an intermediate level. In fact, the purpose of this multi-criteria methodology is not to provide a single score but to highlight blocking points at a level sufficiently precise. Thus, industries know where are the obstructions and therefore where to react. At each step, the level of performance is given by four multicoloured indicators or "radars". An expert system is defined to explain how to take a decision based on the combination of few differing lights.

\subsubsection{A consensus of experts}

It is essential to justify the choice of the criteria and indicators.

The indicator values have to be compared to standards (data or available assessments) or treated by experts [11]. The major data suggested in the BREF are essentially qualitative. As compared to ELV, other standards are difficult to define and often subjective. In fact, the BREF mentions that "the best data 
would relate to production throughput based on surface $\left(\mathrm{m}^{2}\right)$ treated, but little is available on this basis. Most data are for emission concentrations for specific plants, or ranges for sectors or countries." [3]. That's why this methodology (procedures and data) is supplemented with the advice of experts in the metal finishing sector. Therefore, relevance of the possible evaluations and quality of decisions is ensured. These experts happen to possess the great skills and savoir faire to build a reliable, practical and yet simple methodology to be used. Their participation lends a strong sense of authenticity to the L-BAT methodology.

This methodology should encourage industries to change and improve their filing protocols for economic and environmental data. Consequently, the reference could be the data from the previous year.

\section{Case study}

\subsection{A decision-making procedure for surface treatment workshops in general}

Figure 2 presents the main step an operator has to follow to compare the environmental performance of their proper existing techniques to the BAT for the STM (Surface Treatment of Metals) BREF [12].

\subsection{Case study: contribution to the fulfilment of "working reports" for metal finishing workshops}

\subsubsection{A simplified BREF reading grid}

BREF is rarely used by industries. The case of the metal finishing industry is a special situation. At the European level, any technical expert, industry or industrial union was able to give their opinions on the structure and content of this technical document, although none did. Other industrial sectors did participate which is why the metal finishing industry is such an amazing example.

Chapter 5 presents more than 200 techniques for pollution prevention and BAT controls fewer than 18 thematics, a combination of environmental impacts (air emission abatement, waste management, noise reduction...), environmental objectives (drag-out reduction and control, utility inputs and their management, substitution...) and techniques (environmental management tools, process metal recovery...). A similar technique is often mentioned in various scopes.

A simplified version has been created (table 1). Then the new structure was personalized to be useful for specific industries. The metal finishing industry is very sophisticated because of notably the many techniques and operations needed to produce varied products. So after comparing other sectors and some contemplation chapter 5 was reorganized by the main processes and operations of production: degreasing, pickling, bath treatment, bath rinsing and decontamination. Thus, each principal operation of metal finishing treatment is provided with environmental objectives that correspond to BAT. Therefore, this structure highlights the integrated approach. 


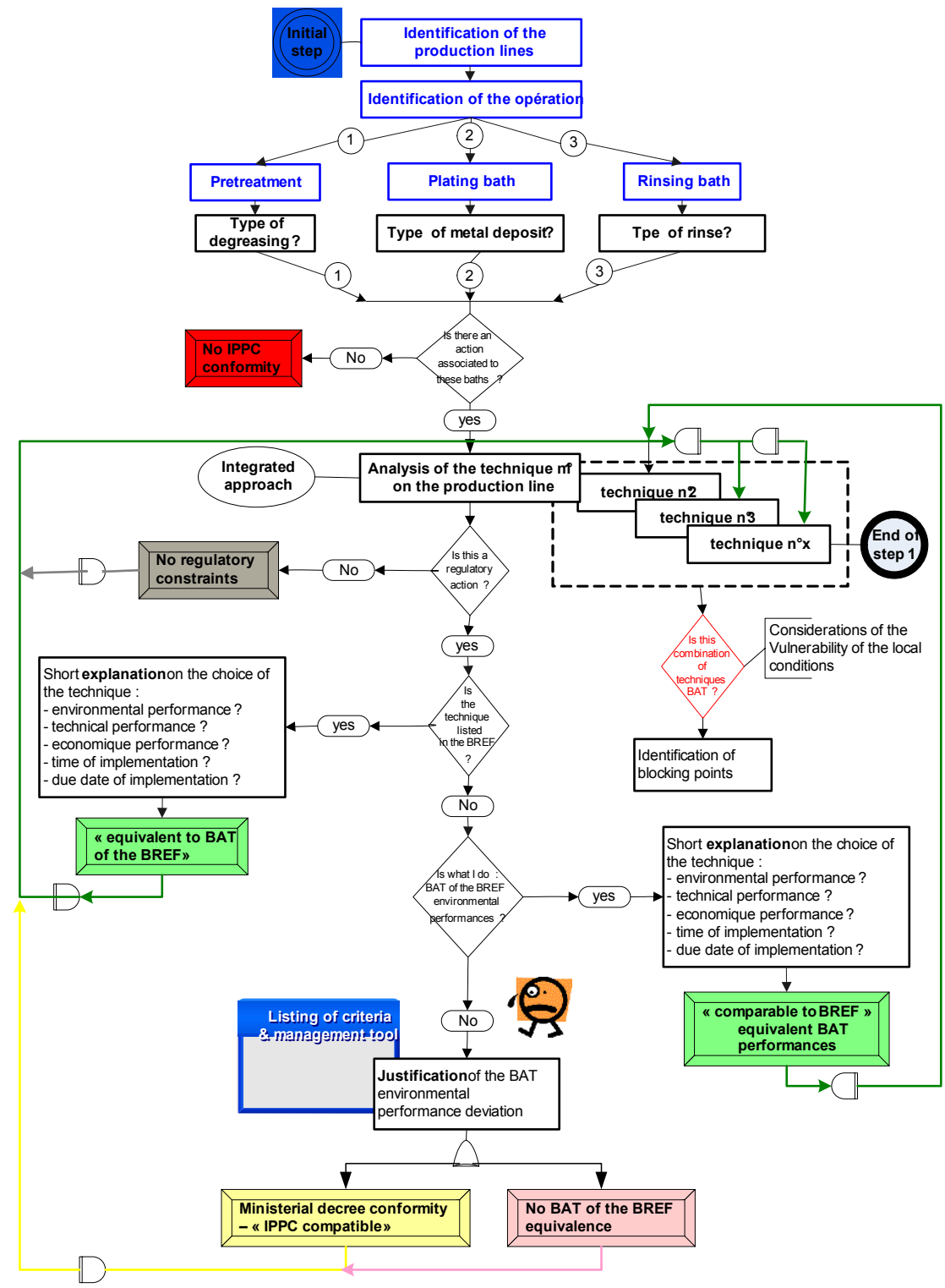

Figure 2: $\quad$ The systematic procedure for the metal finishing industry.

\subsubsection{Qualitative assessment methodology for BAT comparison}

To compare and to validate the in house existing techniques to the environmental performance of the BAT of the BREF, a qualitative methodology with four grades has been developed. 
Table 1: $\quad$ Extract of the TSM BREF for the degreasing operation.

\begin{tabular}{|c|c|c|c|c|c|}
\hline $\begin{array}{c}\text { Functional } \\
\text { unit }\end{array}$ & Processes & \multicolumn{2}{|c|}{ Thematic } & Objectives & BAT Techniques \\
\hline \multirow{14}{*}{$\begin{array}{c}\text { Pre } \\
\text { treatment }\end{array}$} & \multirow{14}{*}{ Degreasing } & \multirow{3}{*}{$\begin{array}{l}\text { Control of } \\
\text { the bath }\end{array}$} & \multirow{3}{*}{$\begin{array}{l}\text { Is there a } \\
\text { type of } \\
\text { bath } \\
\text { agitation? }\end{array}$} & \multirow{3}{*}{$\begin{array}{l}\text { To ensure a } \\
\text { movement of } \\
\text { fresh } \\
\text { solution over } \\
\text { the work } \\
\text { faces }\end{array}$} & Hydraulic turbulence \\
\hline & & & & & $\begin{array}{l}\text { Mechanical agitation of the } \\
\text { workpieces }\end{array}$ \\
\hline & & & & & $\begin{array}{l}\text { Low pressure air agitation } \\
\text { systems }\end{array}$ \\
\hline & & \multirow{5}{*}{\multicolumn{2}{|c|}{ Maintenance? }} & \multirow{5}{*}{$\begin{array}{l}\text { To enhance } \\
\text { the bath } \\
\text { solution life }\end{array}$} & $\begin{array}{l}\text { Filtration with cellulose } \\
\text { filters }\end{array}$ \\
\hline & & & & & $\begin{array}{l}\text { Mechanical separation by } \\
\text { skimmers }\end{array}$ \\
\hline & & & & & Gravity oil separators \\
\hline & & & & & $\begin{array}{l}\text { Centrifugation of degreasing } \\
\text { baths }\end{array}$ \\
\hline & & & & & Membrane filtration \\
\hline & & \multicolumn{2}{|c|}{$\begin{array}{l}\text { Reduction of heating } \\
\text { loss }\end{array}$} & \multirow{4}{*}{$\begin{array}{l}\text { Air } \\
\text { protection }\end{array}$} & $\begin{array}{l}\text { Insulating the surface of } \\
\text { heated tanks by using } \\
\text { floating insulation sections } \\
\text { such as spheres or } \\
\text { hexagonals }\end{array}$ \\
\hline & & \multirow{3}{*}{\multicolumn{2}{|c|}{ Scrubbing of waste air }} & & $\begin{array}{lcr}\text { Table } & 5.4: & \text { indicative } \\
\text { emission ranges } & \text { to air } \\
\text { achieved } & \text { by } & \text { some } \\
\text { installations } & & \end{array}$ \\
\hline & & & & & - droplet separator... \\
\hline & & & & & - wet air scrubber ... \\
\hline & & & & $\begin{array}{l}\text { Recycling } \\
\text { (in-out) }\end{array}$ & \\
\hline & & & & $\begin{array}{l}\text { Drag-in } \\
\text { reduction }\end{array}$ & \\
\hline
\end{tabular}

O Grade 1: There are actions, in accordance with BAT derived from the relevant BREF for the study $O R$ there are actions not indicated in BREF $B U T$ with equivalent BAT environmental performances

- Grade 2: There are actions but not indicated in the relevant BREF for the study BUT in compliance with the ministerial order of the 30 of June 2006 [13] (specific French regulation concerning the metal finishing industry). Therefore, the IPPC compliance is bonded and so in accordance with BAT

- Grade 3: There are actions but not indicated in the BREF AND not in compliance with BAT environmental performances from the relevant BREF for the study

○ Grade 4: There are no actions, hence does not conform to the IPPC directive 


\subsubsection{Results}

The developed model of BREF (table 1) is tested via an actual metal finishing workshop in Saint-Etienne, France. Step by step for each surface treatment processes the operator identifies the existing techniques and compares them to the BAT environmental performance of the TSM BREF. Then after identifying the techniques, the firm evaluates the level of environmental performance for each technique with regard to the four graded qualitative methodology defined in the 3.2.2 section. At present, 33 techniques have been evaluated. Only 3 of them are not in compliance with the BAT concept depending on either the data of the TSM BREF or the concerned ministerial decree. This installation complies for the majority of actions with reference to BAT environmental performance. However, the vulnerability of the natural and human environment is not included in this methodology but studied apart.

This metal finishing workshop was able to present its "working report" to the competent environmental authority on time, before the deadline of October $30^{\text {th }}$. NB: this was not the case for the majority of the IPPC installations.

\section{Perspectives and conclusions}

Generally, "environmental assessment covers a wide range of tools and processes to the prediction and evaluation of environmental effects that are appropriate for different situations" [14]. It is a systematic process that monitors the change over time of the environmental impacts of industrial activities. For industry, increasing environmental performance is more and more anticipated from the elevated pressure of regulations. Nevertheless, the environmental performance assessment faces to many difficulties (organization, decision, methodology, perception). Our L-BAT methodology has the advantage in that it is supported by a multi-criteria hierarchy. 3 main tools have been created to facilitate comparisons to the BAT: an environmental management assessment, a list of evaluation criteria and a simplified BREF reading grid customized for the metal finishing industry. A systematic procedure will help industries to accurately diagnose their existing techniques with regards to BAT as demanded by the IPPC directive. This methodology was ameliorated with stakeholders (administration and industries) via the consideration of their interests. Our participatory approach favours discussions among authorities, researchers, and industry and leads to better decision-making capacities. This collaborative method is actually rather uncommon. On the contrary of other assessment methodologies, the L-BAT is both user friendly and well used by operators.

The L-BAT methodology provides several other advantages. It will favour the realization of "working report in France and more generally corresponds to articles 4, 5, 6 and 13 of the IPPC directive [1] under the BAT concept. In addition, the continuing compliance with the legislation is assured thanks to its systematic approach. Then, with the optimization of the existing processes and evaluation of the potential risks, the approach will encourage the planning of better corrective and preventive actions to continually improve environmental performances. Future work will entail integrating the vulnerability of the local 
environmental conditions with our assessment methodology. By accomplishing this endeavour a better and more accurate assessment should be provided.

\section{Acknowledgements}

The authors are thankful to Chris Yukna for his help with English. The collaboration with Eurothal (a French metal finishing workshop) and all the members of our working group are well appreciated.

\section{References}

[1] Directive (1996) 96/61/EC of 24 September 1996 concerning integrated pollution prevention and control (IPPC)

[2] Arrêté (2004) relatif au bilan de fonctionnement prévu par le décret $\mathrm{n}^{\circ} 77$ 1133 du 21 September 1977 modifié. Decree related to the assessment of industrial function (available only in French).

[3] Bureau Européen pour l'IPPC, "BREF outline and guide”, 2006. Available: http://eIPPCb.jrc.eu

[4] O’Malley, V., The integrated Pollution Prevention and Control (IPPC) Directive and its implications for the environmental and industrial activities in Europe. Sensors and Actuators, pp.78-82, 1999.

[5] Laforest, V., Applying Best Available Techniques in environmental management accounting: from the definition to an assessment method. Environmental Management Accounting for Cleaner production, 15p, 2007.

[6] De Chefdebien, H., (2006) welcome to the world of BAT, (available only in French). http://cyosrv.cyo.fr/ideal/agen

[7] ENDS REPORT, http://www.endsreport.com (November 2007 - issue 394)

[8] ISO 14031, Environmental management system Management environnemental - lignes directrices pour l'évaluation de la performance environnementale, norme européenne - Paris: AFNOR, 35p., 2000.

[9] Saaty, T., Décider face à la complexité: une approche multicritère d'aide à la décision, Entreprise moderne d'édition: Paris, pp.44-76, 1984.

[10] ADEME, comment évaluer les impacts environnementaux au moyen de l'analyse du cycle de vie, pp.4-15, 2005 (available only in French).

[11] Girardin P., Guichard L. \& Bockstaller C., Indicateurs et tableaux de bord - guide pratique pour l'évaluation environnementale, Editions TEC\&DOC, pp. 14-16; 20-26; pp. 31-36, 2005 (available only in French).

[12] European Commission, Institute for Prospective Technological Studies (IPTS), Reference Document on Best Available Techniques for the Surface Treatment of Metals and Plastics, pp. i-xiii; pp.417-449, 2005.

[13] Arrêté (2006) ministériel du 30 juin 2006 relatif aux installations de traitements de surfaces soumises à autorisation au titre de la rubrique 2565 de la nomenclature des installations classées (available only in French).

[14] World Business Council for Sustainable Development (WBCSD), Environmental Assessment: a Business Perspective. 